\title{
Real-Time Implementation of Shunt Active Filter P-Q Control Strategy for Mitigation of Harmonics with Different Fuzzy M.F.s
}

\author{
Suresh Mikkili ${ }^{\dagger}$ and Anup Kumar Panda* \\ ${ }^{+*}$ Dept. of Electrical Engineering, National Institute of Technology - Rourkela, Orissa, India
}

\begin{abstract}
This research article presents a novel approach based on an instantaneous active and reactive power component (p-q) theory for generating reference currents for shunt active filter (SHAF). Three-phase reference current waveforms generated by proposed scheme are tracked by the three-phase voltage source converter in a hysteresis band control scheme. The performance of the SHAF using the p-q control strategy has been evaluated under various source conditions. The performance of the proposed control strategy has been evaluated in terms of harmonic mitigation and DC link voltage regulation. In order to maintain DC link voltage constant and to generate the compensating reference currents, we have developed Fuzzy logic controller with different (Trapezoidal, Triangular and Gaussian) fuzzy M.F.s. The proposed SHAF with different fuzzy M.F.s is able to eliminate the uncertainty in the system and SHAF gains outstanding compensation abilities. The detailed simulation results using MATLAB/SIMULINK software are presented to support the feasibility of proposed control strategy. To validate the proposed approach, the system is also implemented on a real time digital simulator and adequate results are reported for its verifications.
\end{abstract}

Key words: Different fuzzy M.F.s (Trapezoidal, Triangular and Gaussian M.F’s), Fuzzy logic Controller, Harmonic compensation, P-Q control strategy, Shunt active filter

\section{INTRODUCTION}

The shunt active filter (SHAF) is an inverter driven to generate compensating currents that attenuate the harmonic components generated by the nonlinear loads [1]. Therefore, only the fundamental current component would be delivered by the main supply. The performances of active filters depend on the inverter parameters, control method, and the method for current reference determination. Current reference can be obtained by using the band pass filters or the instantaneous power theory [2]. Band pass filters have the disadvantage in that they cause delay of the filtered signal. The instantaneous power theory, on the other hand, is based on complex voltage and current transforms and their inverse transforms. Furthermore, if the voltage source is distorted by harmonics the instantaneous power theory does not provide an accurate basis for active power filters; these become the primary

Manuscript received Feb. 15, 2012; revised Jul. 18, 2012

Recommended for publication by Associate Editor Kyo-Beum Lee.

†Corresponding Author: msuresh.ee@gmail.com

Tel: +91 91787978 67, Fax: +91-661-2462999, N.I.T Rourkela

*Dept. of Electrical Engineering, National Institute of Technology Rourkela, India motivation for the current work.

The objective of this paper is to introduce an efficient controller (Fuzzy logic controller [3] with different membership functions (M.F's)) to obtain the dc link voltage constant and to mitigate the harmonics. The p-q method is used to obtain the current reference for the active power filter. The method for current reference determination is based on extracting the fundamental harmonic from a load current waveform without its phase shifting. In such way the current reference can be obtained simply by subtracting the fundamental harmonic from the measured load current.

The PI controller [4] requires precise linear mathematical models, which are difficult to obtain and may not give satisfactory performance under parameter variations, load disturbances, etc. Recently, fuzzy logic controllers have received a great deal of attention in regards to their application to APFs. The advantages of fuzzy controllers over conventional controllers are that they do not require an accurate mathematical model, can work with imprecise inputs, can handle non-linearity, and are more robust than conventional controllers. The Mamdani type of fuzzy controller, used for the control of an APF [5], gives better 


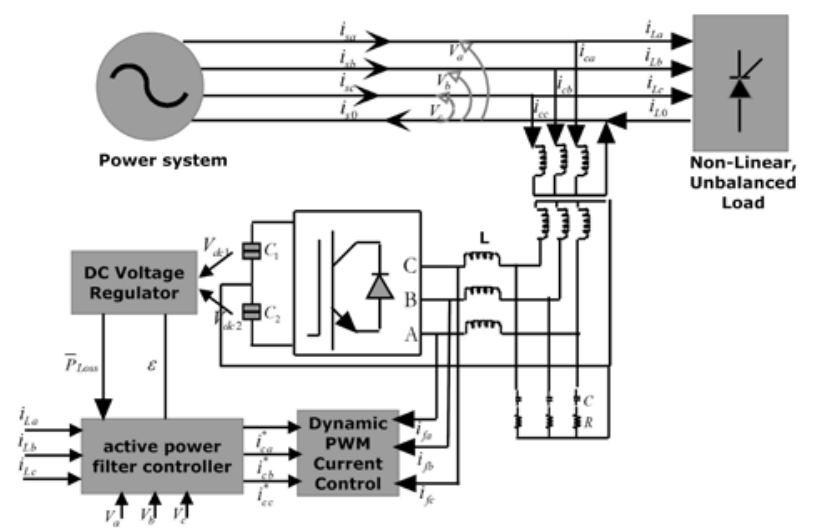

Fig. 1. Three -phase - four wire shunt active filter.

results when compared with PI controllers, but it has the drawback of a larger number of fuzzy sets and 49 rules.

\section{SHUNT ACTIVE FILTER CONFIGURATION}

Fig. 1 shows a basic architecture of three-phase - four wire shunt active filter.

The active power filter [6] is controlled to draw the compensating current from the load to cancel out the current harmonics on AC side and reactive power flow to the source there by making the source current in phase with source voltage.

\section{INSTANTANEOUS ACTIVE AND REACTIVE POWER (P-Q) THEORY}

Instantaneous reactive power theory (or pq theory) was first proposed by Akagi and co-authors in 1984 [7], and has since been the subject of various interpretations and improvements. In this method [13], a set of voltages $\left(\mathrm{v}_{\mathrm{a}}, \mathrm{v}_{\mathrm{b}}\right.$, $\mathrm{v}_{\mathrm{c}}$ ) and currents $\left(\mathrm{i}_{\mathrm{a}}, \mathrm{i}_{\mathrm{b}}, \mathrm{i}_{\mathrm{c}}\right)$ from phase coordinates are first transferred to the $0 \alpha \beta$ coordinates using Clark transformation:

$$
\begin{gathered}
{\left[\begin{array}{c}
v_{\alpha} \\
v_{\beta}
\end{array}\right]=\sqrt{\frac{2}{3}}\left[\begin{array}{ccc}
1 & \frac{1}{2} & \frac{1}{2} \\
0 & \frac{\sqrt{3}}{2} & -\frac{\sqrt{3}}{2}
\end{array}\right]\left[\begin{array}{l}
v_{a} \\
v_{b} \\
v_{c}
\end{array}\right]} \\
{\left[\begin{array}{l}
i_{\alpha} \\
i_{\beta}
\end{array}\right]=\sqrt{\frac{2}{3}}\left[\begin{array}{ccc}
1 & -\frac{1}{2} & -\frac{1}{2} \\
0 & \frac{\sqrt{3}}{2} & -\frac{\sqrt{3}}{2}
\end{array}\right]\left[\begin{array}{l}
i_{L a} \\
i_{L b} \\
i_{L c}
\end{array}\right]} \\
{\left[\begin{array}{c}
p \\
q
\end{array}\right]=\left[\begin{array}{cc}
v_{\alpha} & v_{\beta} \\
v_{\beta} & -v_{\alpha}
\end{array}\right]\left[\begin{array}{l}
i_{\alpha} \\
i_{\beta}
\end{array}\right]}
\end{gathered}
$$

For reactive and harmonic compensation, the entire reactive power and ac component of active power are utilized as the reference power. The reference currents in $\alpha-\beta$ coordinates are calculated by using (5).

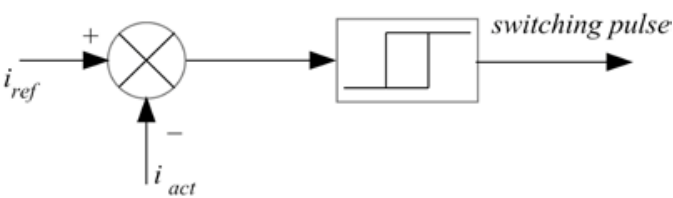

(a)

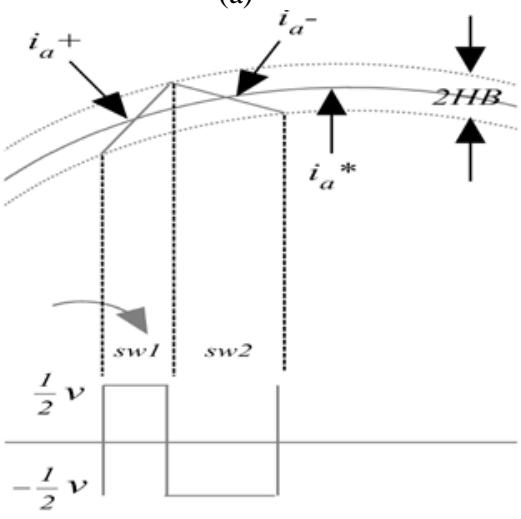

(b)

Fig. 2. (a) Details of voltage and current wave with hysteresis band current contorller. (b) Details of hysteresis band current contorller.

$$
\begin{gathered}
{\left[\begin{array}{c}
i_{c \alpha}^{*} \\
i_{c \beta} *
\end{array}\right]=\frac{1}{v_{\alpha}^{2}+v_{\beta}^{2}}\left[\begin{array}{cc}
v_{\alpha} & v_{\beta} \\
v_{\beta} & -v_{\alpha}
\end{array}\right]\left[\begin{array}{c}
-P_{c}^{*} \\
-q_{c}^{*}
\end{array}\right]} \\
{\left[\begin{array}{l}
i_{c a} * \\
i_{c b} * \\
i_{C C} *
\end{array}\right]=\sqrt{\frac{2}{3}}\left[\begin{array}{cc}
1 & 0 \\
-\frac{1}{2} & \frac{\sqrt{3}}{2} \\
-\frac{1}{2} & -\frac{\sqrt{3}}{2}
\end{array}\right]\left[\begin{array}{l}
i_{c \alpha} * \\
i_{c \beta} *
\end{array}\right]}
\end{gathered}
$$

In addition, PLL (Phase locked loop) employed in shunt filter automatically tracks the system frequency and fundamental positive-sequence component of three phase generic input signal. Appropriate design of PLL allows proper operation under distorted and unbalanced voltage conditions. Controller includes small changes in positive sequence detector as harmonic compensation is mainly concentrated on three phase four wire [9]. As we know in three- phase three wire, $v_{a}{ }^{\prime}, \quad v_{b}{ }^{\prime}, \quad v_{c}{ }^{\prime}$ are used in transformations which resemble absence of zero sequence component and it is given in equation (7). Thus in three phase four wire it was modified as $v_{\alpha}{ }^{\prime}, v_{\beta}{ }^{\prime}$ and it is given in equation (8).

$$
\begin{gathered}
{\left[\begin{array}{c}
v_{a}^{\prime} \\
v_{b}^{\prime} \\
v_{C^{\prime}}
\end{array}\right]=\sqrt{\frac{2}{3}}\left[\begin{array}{cc}
1 & 0 \\
-\frac{1}{2} & \frac{\sqrt{3}}{2} \\
-\frac{1}{2} & -\frac{\sqrt{3}}{2}
\end{array}\right]\left[\begin{array}{c}
v_{\alpha}^{\prime} \\
v_{\beta}^{\prime}
\end{array}\right]} \\
{\left[\begin{array}{c}
v_{\alpha}^{\prime} \\
v_{\beta}^{\prime}
\end{array}\right]=\frac{1}{i_{\alpha}^{\prime 2}+i_{\beta}^{\prime 2}}\left[\begin{array}{cc}
i_{\alpha}^{\prime} & -i \\
i_{\beta}^{\prime} & i_{\alpha}^{\prime}
\end{array}\right]\left[\begin{array}{l}
\bar{p}^{\prime} \\
\bar{q}^{\prime}
\end{array}\right]}
\end{gathered}
$$




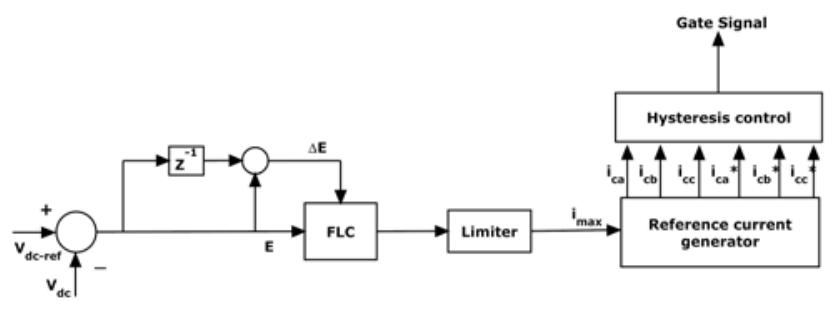

Fig. 3. Proposed Fuzzy logic Controller.

\section{HYSTERESIS CURRENT CONTROLLER}

The hysteresis band current control technique [10] is most suitable for all the applications of current controlled voltage source inverters in active power filters, grid connected systems. The hysteresis band current control is characterized by unconditioned stability, good accuracy, and quick response. The hysteresis band current control idea used for the control of active power filter line current is demonstrated in Figs. 2 (a) and (b).

The actual source currents are monitored instantaneously, and then compared to the reference currents generated by the proposed algorithm. In order to get accurate instantaneous control, switching of IGBT device should be such that the error signal should approach zero, thus providing quick response. For this reason, a hysteresis current controller with fixed band which derives the switching signals of three phase IGBT based VSI bridge is used. The upper device and the lower device in one phase leg of VSI are switched in complementary manner or else a dead short circuit will take a place. The APF [11] reference currents $i_{s a}, i_{s b}, i_{s c}$ compared with sensed source currents $i_{s a}, i_{s b}, i_{s c}$ and the error signals are operated by the hysteresis current controller to generate the firing pulses which activate the inverter power switches in a manner that reduces the current error. The hysteresis band current controller decides the switching pattern of an active power filter.

\section{DC LiNK VOLTAGE REGULATION WITH FUZZY LOGIC CONTROLLER}

For regulating and maintaining the DC link capacitor voltage constant [12], the active power flowing into the active filter needs to be controlled. If the active power flowing into the filter can be controlled equals to the losses inside the filter, the DC link voltage can be maintained at the desired value. The quality and performance of the SHAF depend mainly on the method implemented to generate the compensating reference currents. In order to maintain DC link voltage constant and to generate the compensating reference currents, we have developed a Fuzzy logic controller.

Fig. 3 shows the internal structure of the control circuit. The control scheme consists of FLC [13], limiter, and three

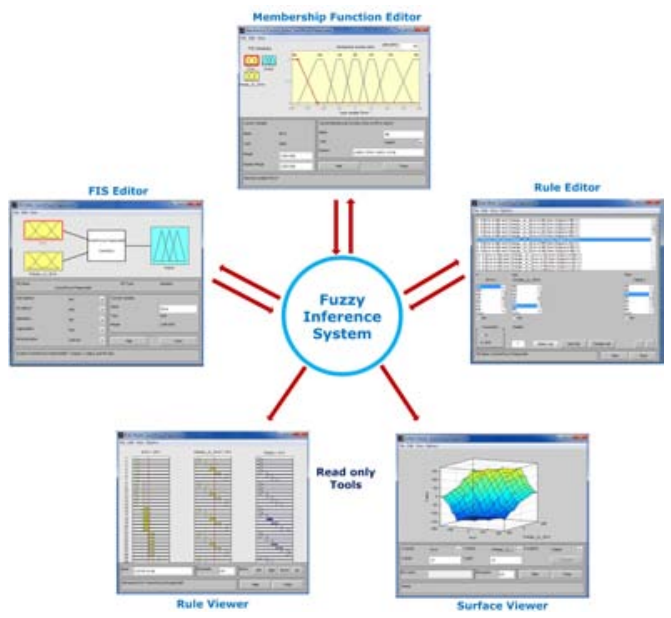

(a)

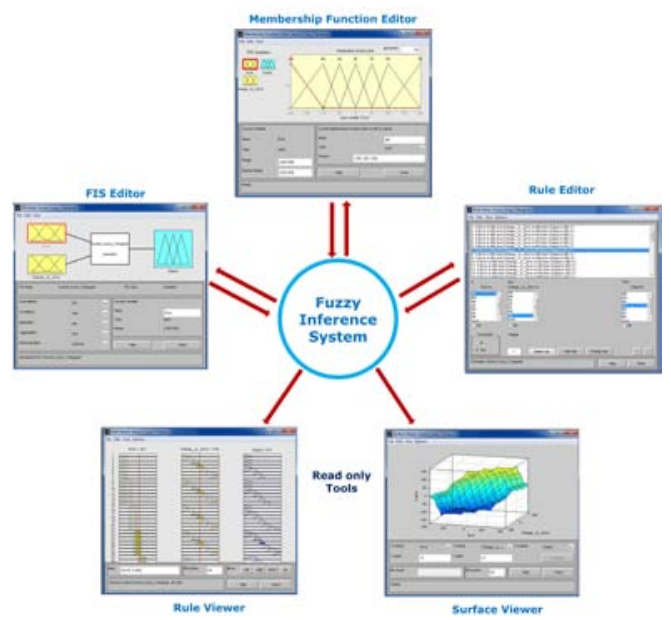

(b)

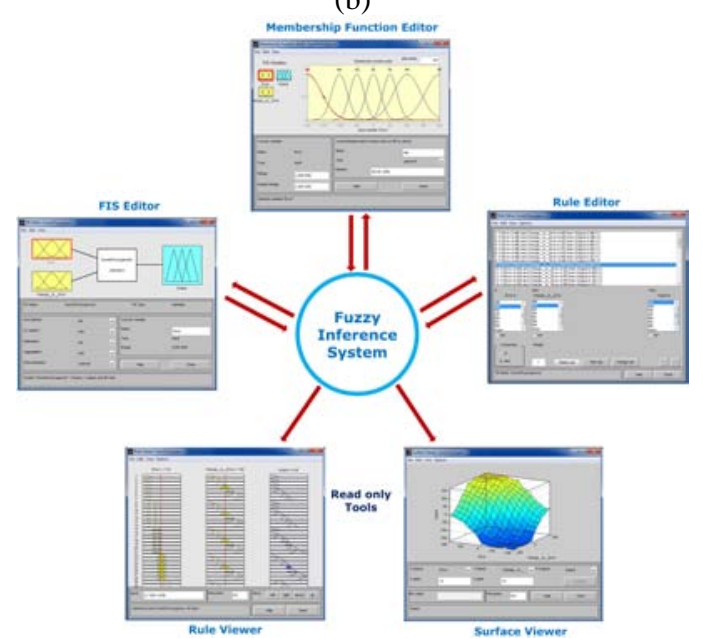

(c)

Fig. 4. (a) Fuzzy Inference System with Trapezoidal M.F. (b) Fuzzy Inference System with Triangular M.F. (c) Fuzzy Inference System with Gaussian M.F.

phase sine wave generator for the generation of reference current and the generation of switching signals. The peak value of reference currents is estimated by regulating the DC 


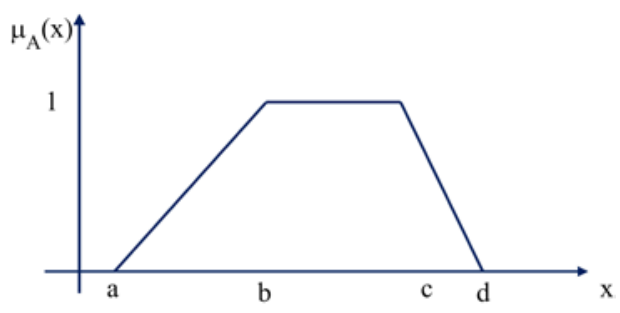

(a)

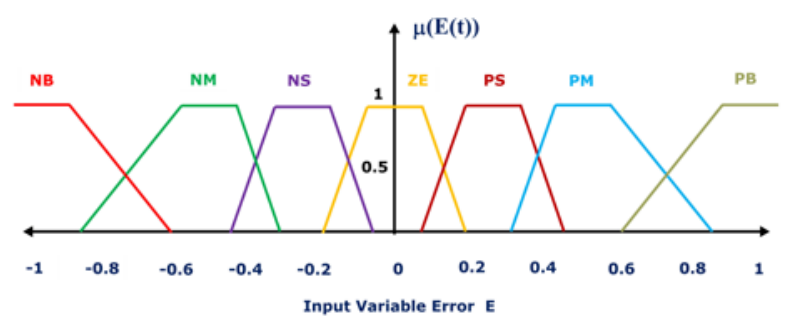

(b)

Fig. 5. (a) Trapezoidal M.F. (b) Input Variable Error 'E' Trapezoidal M.F.

link voltage. The actual capacitor voltage is compared with a set reference value. The error signal is then processed through a Fuzzy controller, which contributes to zero steady error in tracking the reference current signal.

Fig. 4 shows the Fuzzy inference system. The FIS [4] Editor handles the high-level issues for the system: How many inputs and output variables? What are their names? The Membership Function Editor is used to define the shapes of all the membership functions associated with each variable. The Rule Editor is for editing the list of rules that defines the behavior of the system. The Rule Viewer and the Surface Viewer are used for looking at, as opposed to editing, the FIS.

\section{A. Trapezoidal Membership Function}

The trapezoidal curve is a function of a vector, $x$, and depends on four scalar parameters $a, b, c$, and $d$, as given by

$$
\mu_{A}(x)=\max \left(\min \left(\frac{x-a}{b-a}, 1, \frac{d-x}{d-c}\right), 0\right)
$$

The parameters $a$ and $d$ locate the "feet" of the trapezoid and the parameters $b$ and $c$ locate the "shoulders."

\section{B. Triangular Membership Function}

The triangular curve is a function of a vector, $x$, and depends on three scalar parameters $a, b$, and $c$, as given by

$$
\mu_{A}(x)=\max \left(\min \left(\frac{x-a}{b-a}, \frac{c-x}{c-b}\right), 0\right)
$$

The parameters $a$ and $c$ locate the "feet" of the triangle and the parameter $b$ locates the peak.

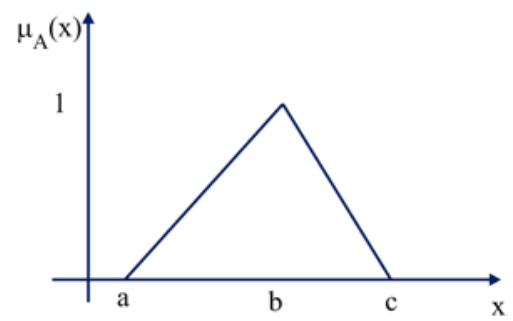

(a)

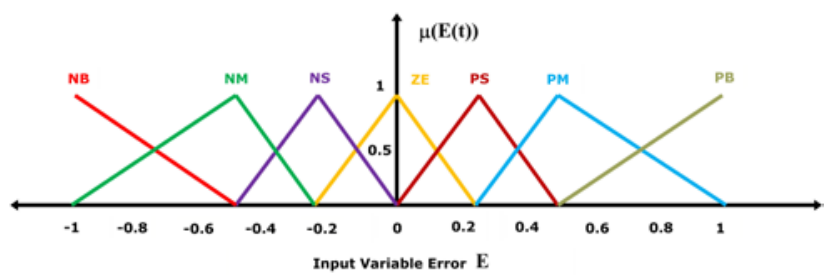

(b)

Fig. 6. (a) Triangular M.F. (b) Input Variable Error ' $E$ ' Triangular M.F.

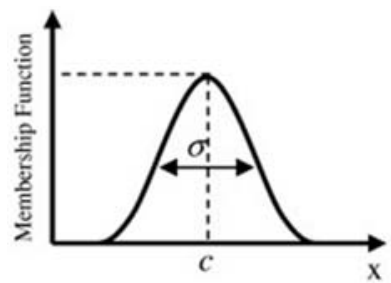

(a)

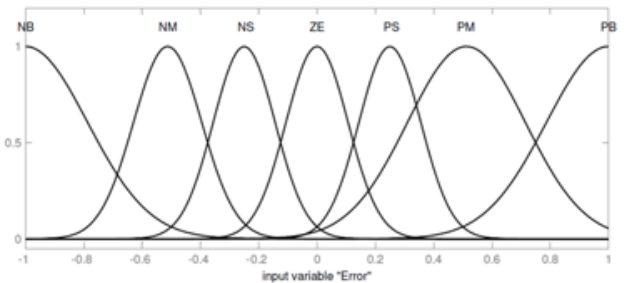

(b)

Fig. 7. (a) Gaussian M.F. (b) Input Variable Error 'E' Gaussian M.F.

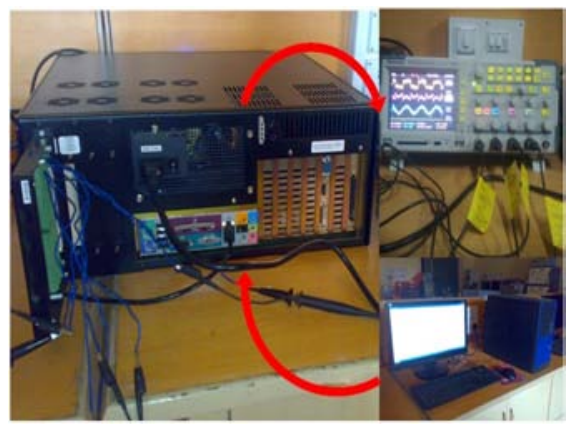

Fig. 8. RTDS Hardware.

\section{Gaussian membership function}

$$
\mu_{A}(x, c, s, m)=\exp \left[-\frac{1}{2}\left|\frac{x-c}{s}\right|^{m}\right]
$$

Where c: centre $s$ : width $m$ : fuzzification factor (e.g., $m=2$ ) 
Real-Time Implementation of Shunt Active Filter P-Q Control Strategy for ...

825
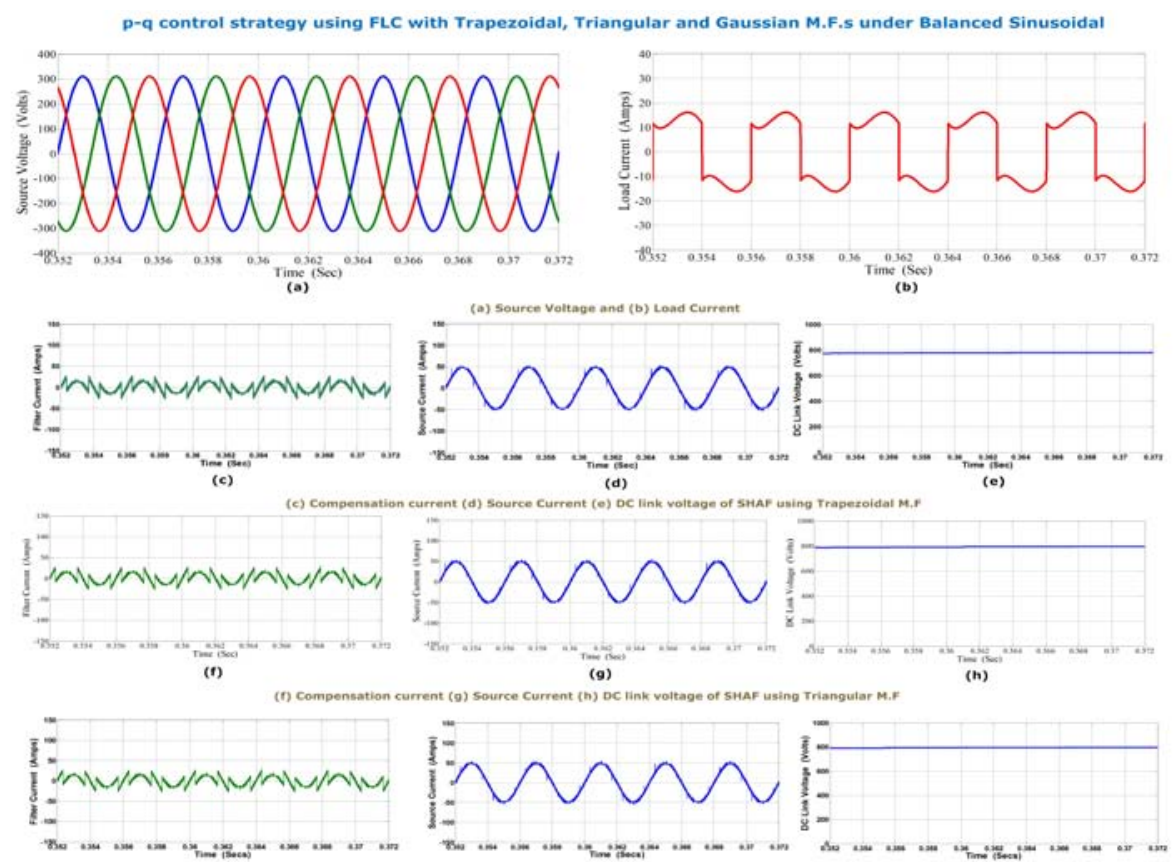

(i)
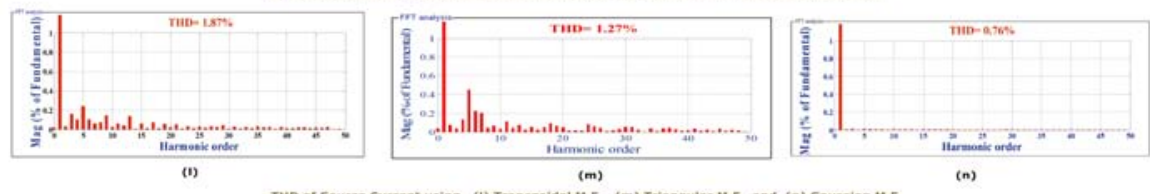

THD of Source Current using (1) Trapexoidal M.F (m) Triangular M.F and (n) Gaussian M.F

(n)
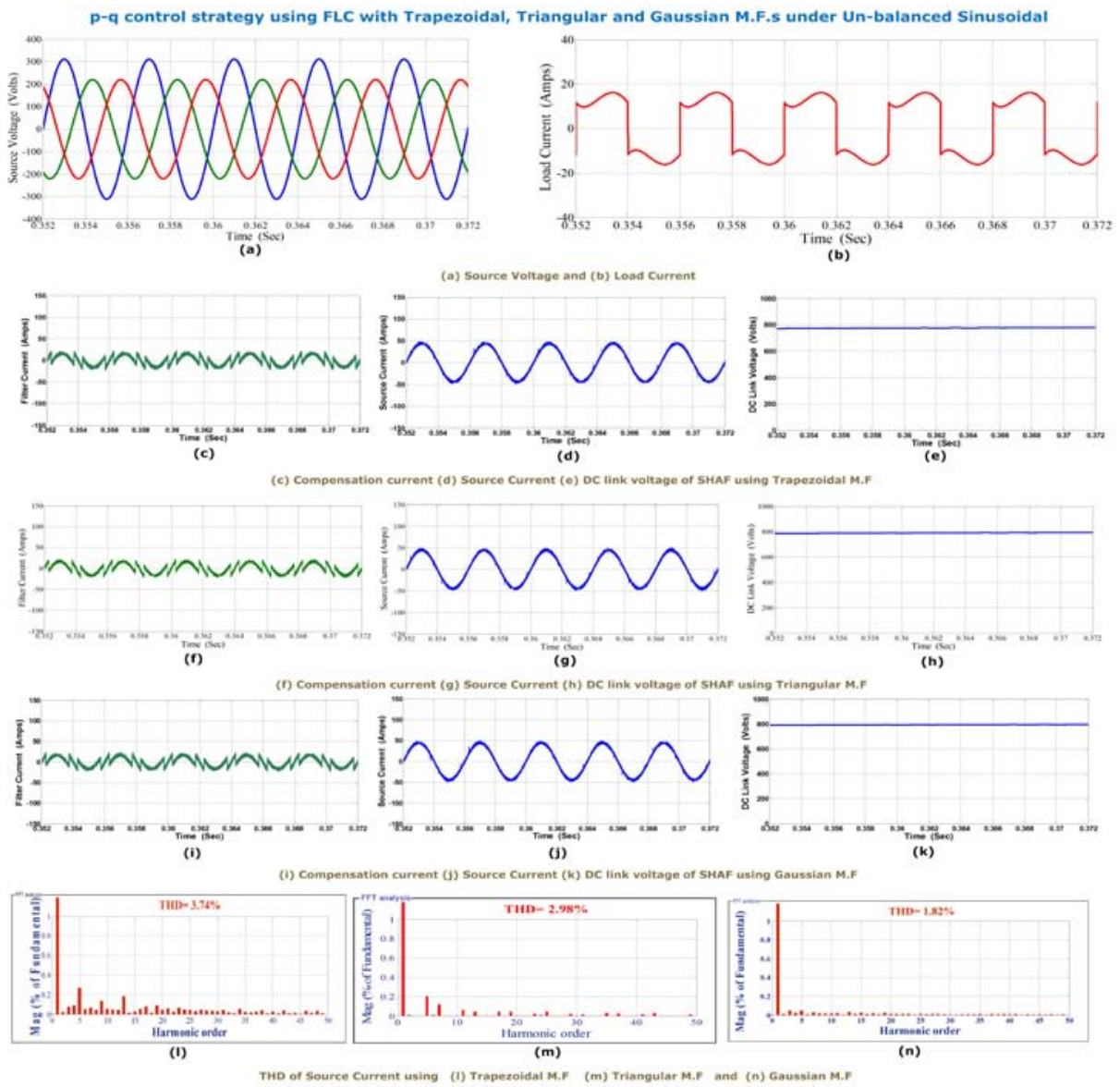


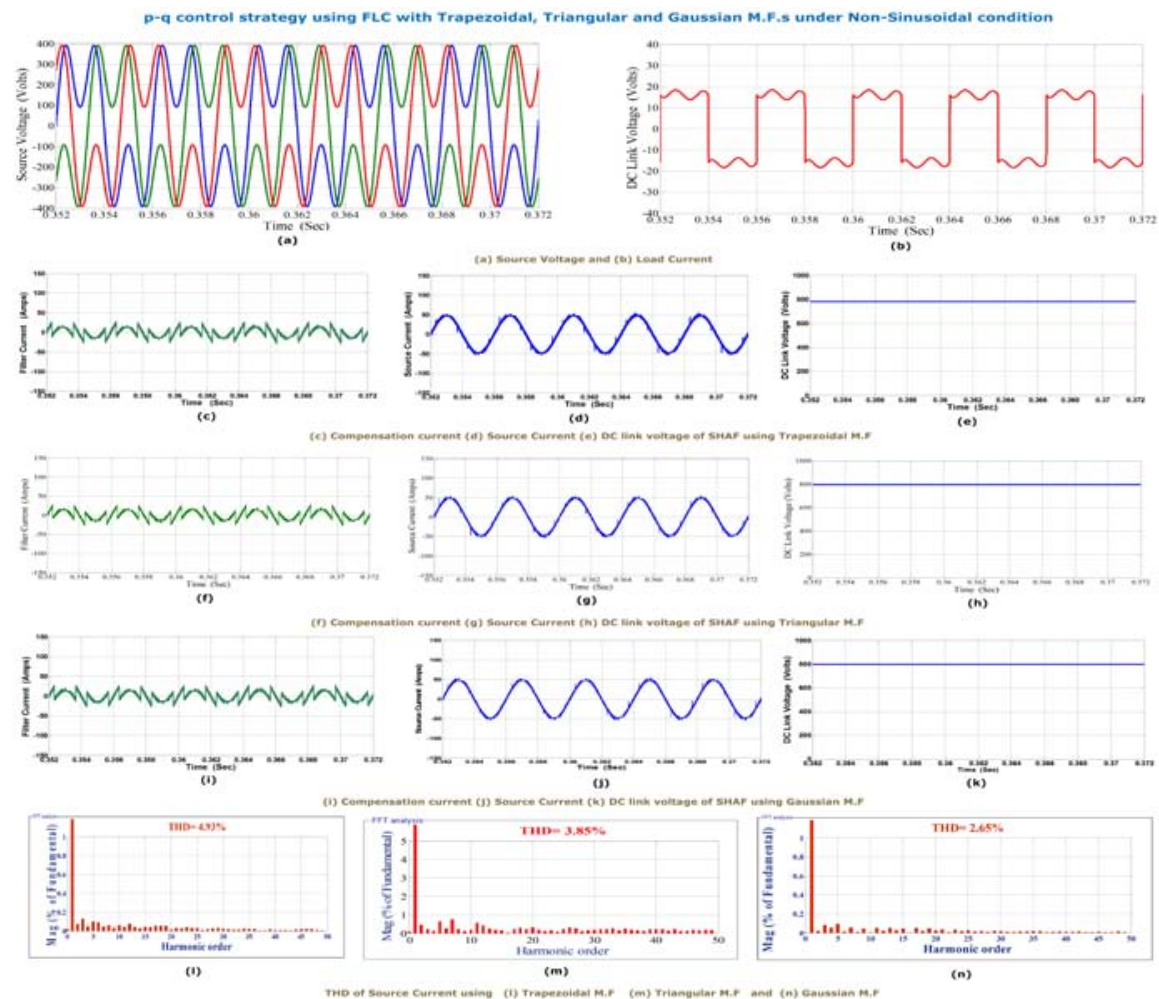

Fig. 9. SHAF response using p-q control strategy with FLC under balanced, un-balanced and non- Sinusoidal condition using MATLAB. (a) Source Voltage. (b) Load Current. (c) Compensation current using Trapezoidal M.F. (d) Source Current with filter using Trapezoidal M.F. (e) DC Link Voltage using Trapezoidal M.F. (f) Compensation current using Triangular M.F. (g) Source Current with filter using Triangular M.F. (h) DC Link Voltage using Triangular M.F. (i) Compensation current using Gaussian M.F. (j) Source Current with filter using Gaussian M.F. (k) DC Link Voltage using Gaussian M.F. (l) T.H.D of Source current with Trapezoidal M.F. (m) T.H.D of Source current with Triangular M.F. (n) T.H.D of Source current with Gaussian M.F.

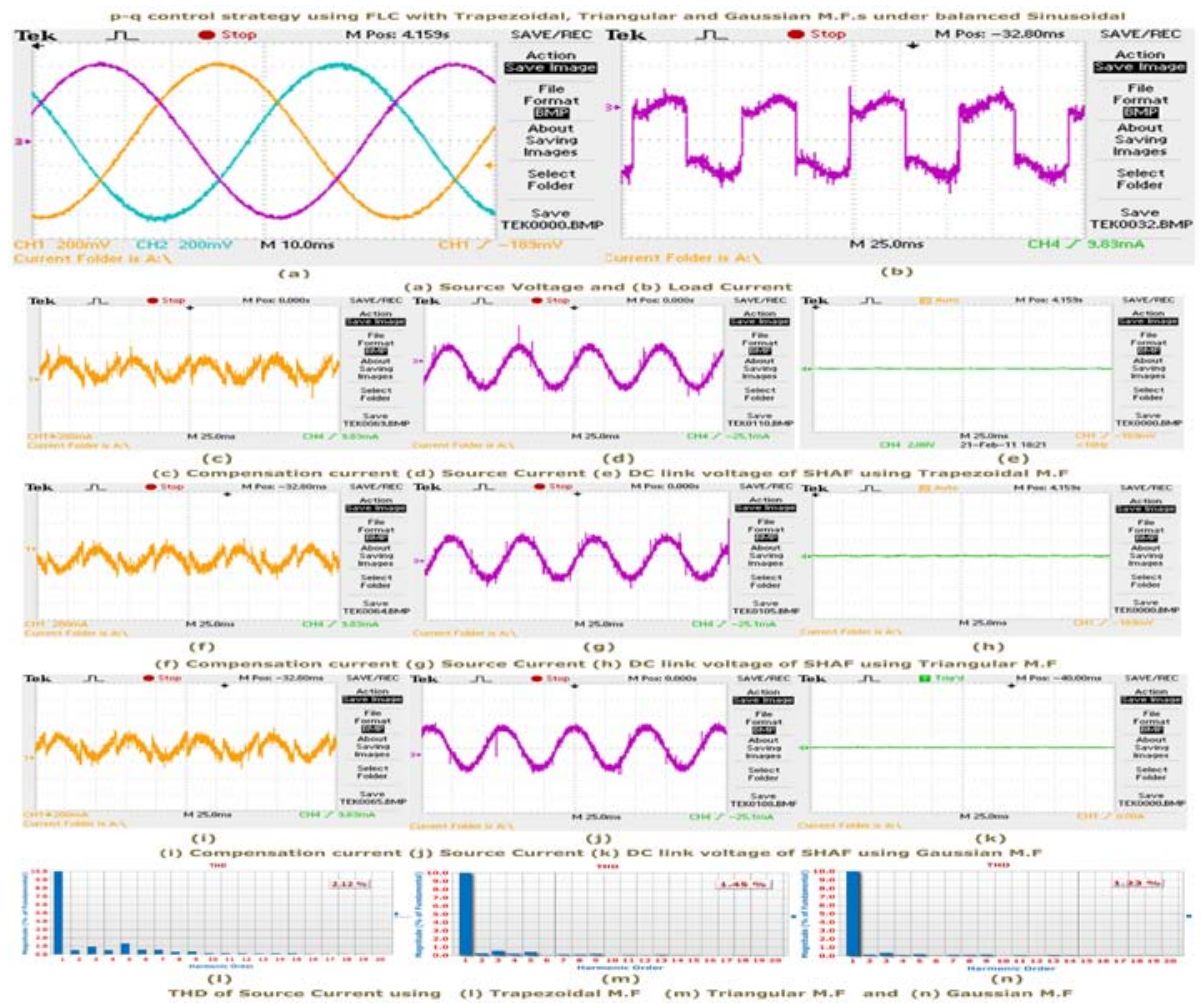



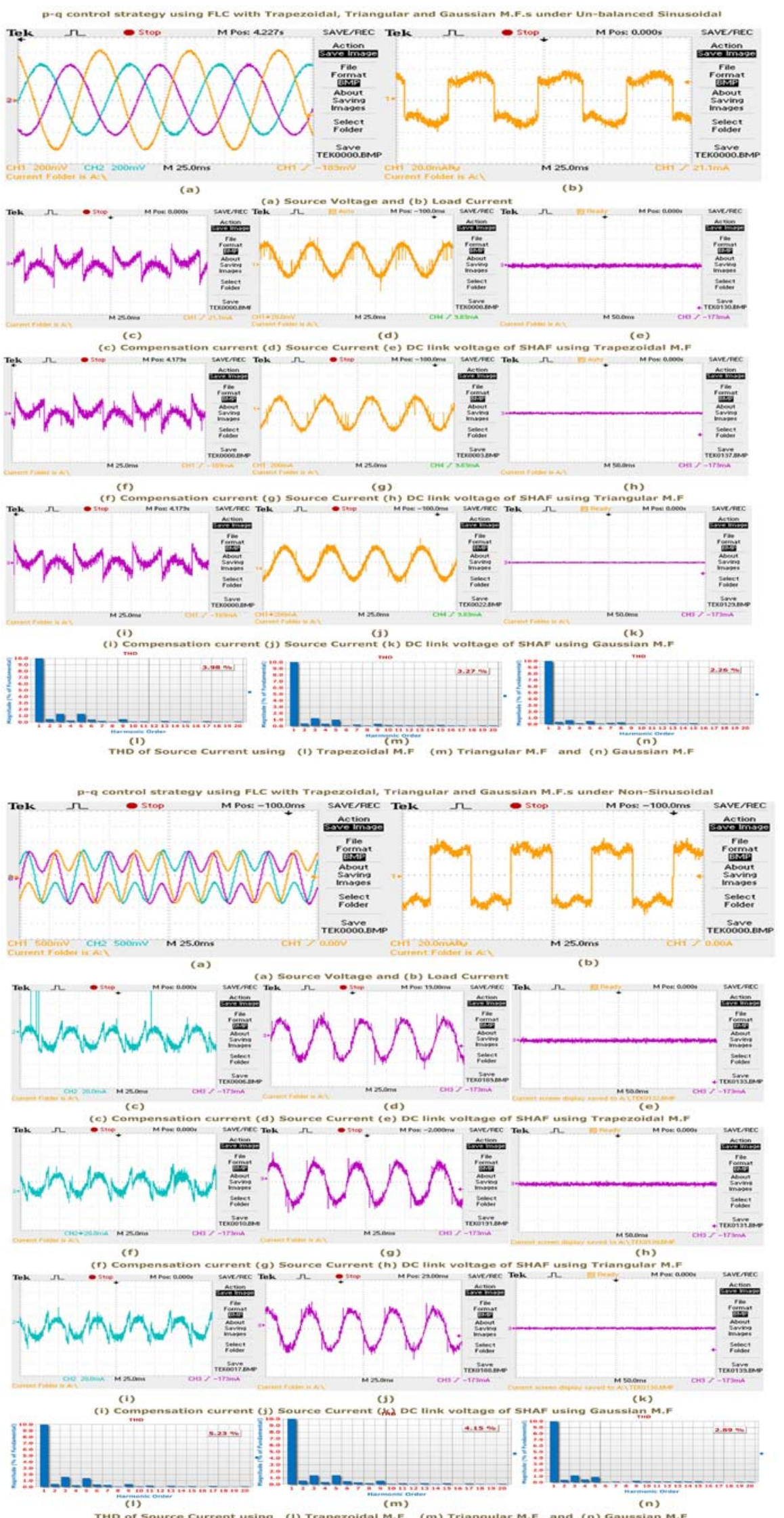

Fig. 10. SHAF response using p-q control strategy with FLC under balanced, un-balanced and non- Sinusoidal condition using.RTDS. 


\section{RTDS HARDWARE}

This simulator was developed with the aim of meeting the transient simulation needs of electromechanical drives and electric systems while solving the limitations of traditional real-time simulators which is shown in Fig. 8.

It is based on a central principle: the use of widely available, user-friendly, highly competitive commercial products (PC platform, Simulink ${ }^{\mathrm{TM}}$ ). The real-time simulator [13] consists of two main tools: a real-time distributed simulation package (RT-LAB) for the execution of Simulink block diagrams on a PC-cluster, and algorithmic toolboxes designed for the fixed-time-step simulation of stiff electric circuits and their controllers. Real-time simulation and Hardware-In-the-Loop (HIL) applications are increasingly recognized as essential tools for an engineering design and especially in power electronics and electrical systems. The OP5142 is one of the key building blocks in the modular OP5000 I/O system from Opal- RT Technologies. It allows the incorporation of FPGA technologies in RT-LAB simulation clusters for distributed execution of HDL functions and high-speed, high-density digital I/O in real-time models. Based on the highest density Xilinx Spartan-3 FPGAs, the OP5142 can be attached to the backplane of an I/O module of either a Wanda 3U- or Wanda 4U-based Opal-RT simulation system.

\section{SiMULATION AND REAL-TIME RESULTS}

Fig. 9 and Fig. 10 give the details of a source voltage, a load current, a compensation current, a source current with filter, a DC link voltage under balanced, un-balanced and non-sinusoidal supply voltage conditions with different fuzzy M.F's using Matlab and RTDS Hardware respectively.

The THD of $\mathrm{p}$-q method with PI controller under balanced, un-balanced and non-sinusoidal conditions using Matlab it is $2.15 \%, 4.16 \%$ and $5.31 \%$ respectively and using RTDS is $2.21 \%, 4.23 \%$ and $5.41 \%$ respectively. The mitigation of harmonics is poor when the THD is high. Under un-balanced and non-sinusoidal conditions, the PI controller is unable to mitigate harmonics completely and THD becomes near to 5. But according to IEEE 519-1992 standard, THD must be less than 5 . Therefore, in order to mitigate harmonics completely, we have considered FLC with different MFs.

Initially the system performance is analyzed under balanced sinusoidal conditions, during which the FLC with all M.F's (Trapezoidal, Triangular and Gaussian) are good enough at suppressing the harmonics and THD to about $1.87 \%, 1.27 \%$ and $0.76 \%$ using Matlab. The THD of $\mathrm{p}-\mathrm{q}$ control strategy using RTDS is $2.12 \%, 1.45 \%$ and $1.23 \%$.

The total harmonic distortion (THD) of the FLC with Trapezoidal M.F under unbalanced condition is $3.74 \%$ and under non-sinusoidal condition is $4.93 \%$ using Matlab and the respective THDs of SHAF using RTDS are $3.98 \%$ and $5.23 \%$ respectively.

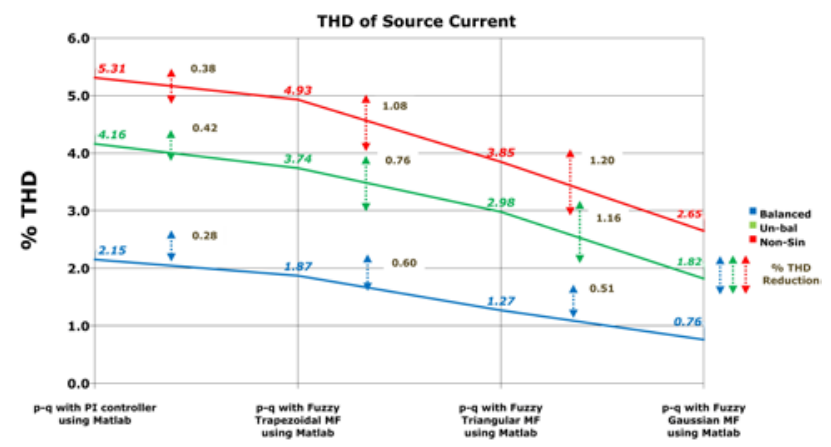

(a)

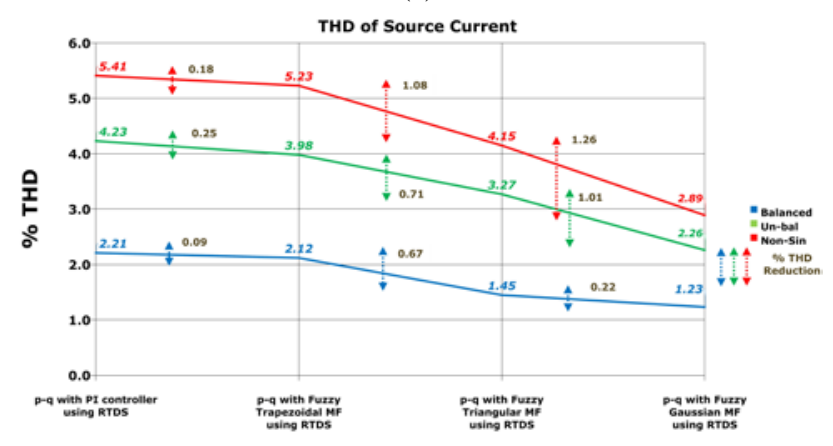

(b)

Fig. 11. (a) THD of Source Current for p-q method using PI controller and FLC with different M.F's using MATLAB. (b) THD of Source Current for p-q method using PI controller and FLC with different M.F's Using RTDS.

The THD of the FLC with Triangular M.F under unbalanced condition is to about $2.98 \%$ and under non-sinusoidal condition is about $3.85 \%$ using Matlab and the respective THDs of SHAF using RTDS are $3.27 \%$ and $4.15 \%$ respectively.

The THD of the FLC with Gaussian M.F under unbalanced condition is about $1.82 \%$ and under non-sinusoidal condition is about $2.65 \%$ using Matlab and the respective THDs of SHAF using RTDS are $2.26 \%$ and $2.89 \%$ respectively.

Fig. 11 clearly illustrates the amount of THD reduced from method to method under balanced, unbalanced and non-sinusoidal conditions using Matlab and RTDS Hardware respectively.

When the source voltages are balanced and sinusoidal, all Fuzzy membership functions converge to the same compensation characteristics. However, under unbalanced and non-sinusoidal source voltage conditions, the FLC with Gaussian M.F shows superior performance over the FLC with trapezoidal and triangular M.F. While considering Trapezoidal M.F, SHAF has succeeded in compensating harmonic currents, but notches are observed in the source current. The main reason behind the notches is that the controller failed to track the current correctly and thereby APF fails to compensate harmonics completely. It is observed that, source current waveform is somewhat good; 
notches in the waveform are eliminated by using triangular M.F. Nevertheless by using Gaussian M.F, the source current waveform is very good; notches in the waveform are eliminated.

\section{CONCLUSION}

In the present paper instantaneous real active and reactive power $(p-q)$ control strategy has been used for the three-phase four-wire distribution SHAF system to improve the performance under balanced, un-balanced and non-ideal supply voltage conditions. Fuzzy logic controller with different M.F.s has been chosen. The control scheme using three independent hysteresis current controllers have been implemented. The operation and modeling of the SHAF have been described. The simulation results are validated with real-time implementation on RTDS hardware. The Real-time implementation and simulation results showed that even if the supply voltage is non-sinusoidal the performance with p-q theory using FLC with Gaussian M.F comfortably outperformed the results obtained with p-q theory using PI Controller and FLC with trapezoidal and triangular M.F.

While considering the $\mathrm{p}-\mathrm{q}$ theory using FLC with Gaussian M.F, the SHAF has been found to meet the IEEE 519-1992 standard recommendations on harmonic levels, making it easily adaptable to more severe constraints such as highly distorted and unbalanced supply voltage. The control approach has compensated the neutral harmonic currents and the dc bus voltage of SHAF is almost maintained at the reference value under all disturbances, which confirm the effectiveness of the controller.

\section{REFERENCES}

[1] B. Singh, P. Jayaprakash, and D. P. Kothari “a three-phase four-wire dstatcom for power quality improvement,” Journal of Power Electronics, Vol. 8, No. 3, pp. 259-267, Jul. 2008.

[2] Peng Z. Peng, G. W. Ott JR., and D. J. Adams, "Harmonic and reactive power compensation based on the generalized instantaneous reactive power theory for three-phase four-wire systems,” IEEE Trans. Power Electron., Vol. 13, No. 6, pp. 1174-1181, Nov. 1998.

[3] S. K. Jain, P. Agrawal, and H. O. Gupta, "PI and Fuzzy logic controlled shunt active power filter for power quality improvement," IEEE Proceedings Electric Power Applications, Vol. 149, No. 5, 2002.

[4] Suresh Mikkili and A. K. Panda, "PI and fuzzy logic controller based 3-phase 4-wire shunt active filter for mitigation of current harmonics with $\mathrm{i}_{\mathrm{d}}-\mathrm{i}_{\mathrm{q}}$ control strategy,” Journal of power Electronics, Vol. 11, No. 6, pp. 914-921, Nov. 2011.

[5] Montero M. I. M et al. "Comparison of control strategies for shunt active power filters in three-phase four-wire systems," IEEE Trans. Power Electron., Vol. 22, No. 1, pp. 229-236, Jan. 2007.

[6] L. Gyugyi and E. C. Strycula, “Active AC power filters," IEEE IIAS Annual Meeting, p. 529, 1976.
[7] H. Akagi, Y. Kanazawa, and A. Nabae, "Instantaneous reactive power compensators comprising switching devices without energy storage components," IEEE Trans Industry Appl., Vol. Ia-20, No. 3, pp 625-630, May/Jun. 1984.

[8] H. Akagi, E. H. Watanabe, and M. Aredes, Instantaneous Power Theory and Applications to Power Conditioning, IEEE Press/Wiley-Inter-science, 2007.

[9] Aredes M. et al. "Three-phase four-wire shunt active filter control strategies," IEEE Trans. Power Electron., Vol. 12, No. 2, pp. 311-318, Mar. 1997.

[10] J. Holtz, "Pulse width modulation - A survey," IEEE Trans. Industrial Electron., Vol. 39, No. 5, pp. 410-420, Oct. 1992.

[11] P. Rodriguez, J. I. Candela, A. Luna, and L. Asiminoaei, "Current harmonics cancellation in three-phase four-wire systems by using a four-branch star filtering topology," IEEE Trans. Power Electron., Vol. 24, No. 8, pp. 1939-1950, Aug. 2009.

[12] F. Mekri, B. Mazari, and M. Machmoum, "Control and optimization of shunt active power filter parameters by fuzzy logic," IEEE Electrical and computer Engineering, Vol. 31, No. 3, pp. 127-134, Jan. 2006.

[13] S. Mikkili, A. K. Panda, "Real-time implementation of PI and fuzzy logic controllers based shunt active filter control strategies for power quality improvement," International Journal of Electrical Power and Energy Systems, Vol. 43, No. 1, pp. 1114-1126, 2012.

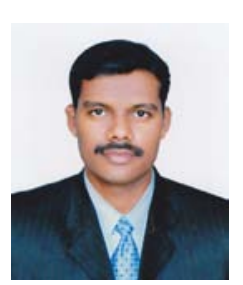

Suresh Mikkili was born in Bapatla, Andhra Pradesh, India on $5^{\text {th }}$ Aug 1985. He received B.Tech degree in Electrical and Electronics Engineering from S.I.T.E, T.P.Gudem affiliated to JNTU University Hyderabad, Andhra Pradesh, India in May 2006 and Masters (M.Tech) in Electrical Engineering from N.I.T Rourkela, Orissa, India in May 2008. He has worked as a Asst. Prof in Electrical Engineering in distinguished engineering colleges from June 2008 to July 2010. He is currently pursuing Ph.D degree in Electrical Engineering at N.I.T Rourkela, Orissa, India. His main area of research includes Power quality improvement issues, Active filters, and Applications of Soft Computing Techniques.

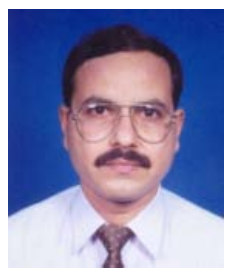

Anup Kumar Panda received the B.Tech in Electrical Engineering from Sambalpur University, India in 1987. He received the M.Tech in Power Electronics and Drives from Indian Institute of Technology, Kharagpur, India in 1993 and Ph.D. in 2001 from Utkal University. Join as a faculty in IGIT, Sarang in 1990. Served there for eleven years and then join National Institute of Technology, Rourkela in January 2001 as an assistant professor and currently continuing as a Professor in the Department of Electrical Engineering. He has published over fifty articles in journals and conferences. He has completed two MHRD projects and one NaMPET project. Guided three Ph.D. scholars and currently guiding four scholars in the area of Power Electronics \& Drives. His research interest include analysis and design of high frequency power conversion circuits, power factor correction circuits, power quality improvement in power system and electric drives, Applications of Soft Computing Techniques. 